\title{
Application of the art farmland landscape to rural landscape : A study case of Landscape Design at Xihe valley in Qionglai,Sichuan
}

\author{
Feiyu $\mathrm{Pu}^{1,}$, , Jingwen $\mathrm{Xu}^{1, \mathrm{~b}^{*}}$,Junfang $\mathrm{Zhao}^{2}$,Ning $\mathrm{Li}^{1}$ and Surong Xiang ${ }^{1}$ \\ ${ }^{1}$ College of Resources, Sichuan Agricultural University, Chengdu 611130, China \\ ${ }^{2}$ Chinese Academy of Meteorological Sciences, CMA, Beijing 100081, P.R. China \\ a email: blinkpfy@163.com, ${ }^{\star b}$ Corresponding author: x.j.w@163.com
}

Keywords: art farmland; landscape planning; crops

Abstract. The article puts forward the concept of art farmland,summarizes its characteristics and principles of rural landscape planning. Taking Landscape Design at Xihe valley in Qionglai,Sichuan as an example.Discussing the application of the art farmland landscape to rural landscape from the design idea and the function of art farmland.Providing reference for farmland designs of landscape planning in the future.

\section{Introduction}

With the development of social economy and the acceleration of urbanization,the natural and traditional rural landscape is dying.As people's living standard has increased,they started to enjoy life and gradually realized the importance of environmental protection.City people yearn for the simple and quiet life of the country, prompting a growing number of rural planning. The four basic characteristics of rural landscape planning are ecological features,naturalness features,rural features and regional features. This article is going to explore rural landscape planning of Xihe valley ecological town in the artistic quality.

\section{The concept and characteristics of art farmland}

\section{The concept of art farmland}

Art farmland is planning and design of agricultural plants and field, forest, production facilities, and other elements, using artistic techniques and other engineering based on the Aesthetics, Garden art, Landscape ecological theory to have a certain artistic effect of farmland and achieve a bumper harvest of material products, art products and leisure products of agriculture[1].

\section{The landscape features of art farmland}

Art farmland not only keeps the features of ecological features,naturalness features,rural features and regional features, but also add the artistic effect.Applying the art means in the planning and design that can strengthen the interest and appreciation.

\section{The ecological features of art farmland}

The farmland ecosystem,centered around crops,constituted the exchanges of mass and energy of biotic community and ecological environment.In order to enhance the artistic effect,we can plant many kinds of plants.More complex the types, more stable the structure, more perfect the function, the greater this throughput and the higher this self-control ability.It can not only increase the agricultural production capacity, but also be advantageous to the farmland ecological balance[2].

\section{The regional features of art farmland}

The design of art farmland has to consider not only the artistic effect, but also the local geography, climate and characteristics.Different geographical environment will make different tillage practices, also can form the different landscape.The differences of climate decide the major crops and the different growth status in different seasons of crops. To create a special zone, we can use the local crops which as a representative sample.For example,the Gold frog of Taomi New village in Nantou,Taiwan. 


\section{The flexibility of art farmland}

The flexibility of art farmland including the dynamic change of farmland and the enthusiasm of people. The dynamic change of farmland including the change of agricultural production activities in different seasons and the change of the color, shape, smell of crops in different seasons.For example,the color of rapeseed is from green to yellow.Art farmland not only provides for people to watch, but also encourages people to participate in it and experience the process of farming activity.

\section{The principles of rural landscape planning and design}

In order to promote farming culture and inherit the local folk culture, we should put agricultural production and environmental protection in an important position in the process of rural landscape planning and design.

\section{The Integrity Principle}

The same region with the fusion of various landscape elements should be as a whole to consider in the process of planning and design.

\section{The ecological principles-art for "blanking"}

In the process of planning and design,we should retain the original local ecological environment. Trees, buildings should not be arbitrarily broken down, and all buildings, local crops should not be transformed. Rustic farm tools and construction should be retained. The planning and design will be more interesting with the original rural life.

\section{The inheritance}

The local characteristic of culture should be retained and inherited. Repairing the folk architecture, carrying forward the folk culture. We should not only retain the custom, but also promote them with the form of activities.

\section{Practice Case}

\section{Project to Overview}

The project locates in Zhongshan Community, Shui kou Town, Qiong lai City. It's about 98 kilometers apart from Chengdu, about $7 \mathrm{~km}$ away form Qionglai City, and about $116 \mathrm{~km}$ away from Shuangliu International Airport.

The town is about $20 \mathrm{~km}$ length from east to west and $6 \mathrm{~km}$ width form north to south which is the largest town in the west gate of Qionglai City. However, the Qiong Lu road belongs to Tiantai Shan national tourist attraction throughout the whole territory.

The project location belongs to subtropical humid monsoon climate zone which is rich in water resources extremely, and it has beautiful natural scenery, rich vegetation, suitable climate. This is a place suitable for planting crops.

\section{The overall design of art farmland}

As a post disaster reconstruction projects, farmland has been to build a high standard farmland.So we don' t use any complex graphics and achieve the artistic effect by taking turns to plant crops.

The design idea of abstractionism painting style,the art structure of farmland is derived from the design of "Mondrian Style", it is shown in Figure.1.Creating an artistic effect that is very succinct, very quiet, very harmonious, and with a little mysterious allure. This artistic effect is exactly what we want.We hope create the most artistic effect farmland with the simplest color, the simplest farmland crops.

The basic elements of painting: linear and right angle (horizontal and vertical) ,three primary colors (red,yellow and blue), non-pigmented (white,grey and black) combined with abstract thinking that is used to symbolize the forces of nature and nature. This design idea follows the principle of nature and ecology.we make it without intervention,foil artistic effect with the simplest crops with local color. 


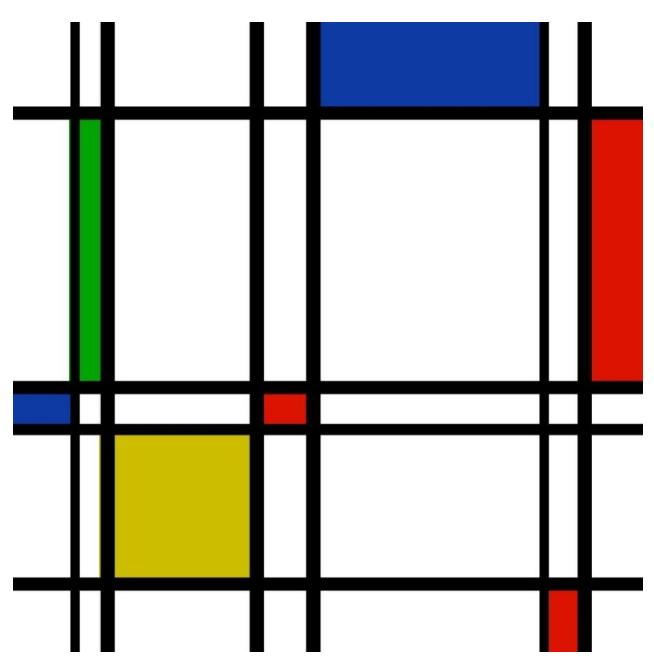

Figure.1 Mondrian's grid

brief design

The brief design is shown in Table.1.

a)Ditches and roads can be used as a fixed color elements. We can structure border color of each grid with perennial vegetation or dye the roads and canals with the color what we need.Artificial coloring will use more rich colors, but requires constant maintenance.

b)Avoiding crop simplification, to achieve an orderly combination of crop diversity (we arrangement a variety of crops in accordance with a certain area, shape and position).Different areas of farmland can be not only suitable for different crop areas ,but also can adapt to the needs of different customers.

c)We can scatter arrangement fish ponds or reservoirs what can be used for water and fish.Reducing the water conveyance way of power and human, and using the nearest water for farmland irrigation.

Table.1 The arrangement of crops

\begin{tabular}{|c|c|c|c|}
\hline crops & months & color & added value \\
\hline Lotus leaf,Lotus & From April to June & $\begin{array}{l}\text { blue, green and } \\
\text { pink }\end{array}$ & $\begin{array}{l}\text { Lotus seeds and lotus root as } \\
\text { byproducts }\end{array}$ \\
\hline Rice & $\begin{array}{l}\text { From May to } \\
\text { September }\end{array}$ & golden yellow & Crops \\
\hline sorghum & $\begin{array}{l}\text { From April to } \\
\text { September }\end{array}$ & red & Economic crops \\
\hline wheat & $\begin{array}{l}\text { From October to } \\
\text { may of next year }\end{array}$ & golden yellow & Crops \\
\hline marigold & $\begin{array}{l}\text { From April to } \\
\text { October }\end{array}$ & golden yellow & Medicinal value \\
\hline $\begin{array}{l}\text { Capsicum } \\
\text { frutescens var }\end{array}$ & $\begin{array}{c}\text { From March to } \\
\text { August }\end{array}$ & red, yellow & Economic crops \\
\hline sunflower & From April to July & yellow & By-products: sunflower seeds \\
\hline rapeseed & $\begin{array}{c}\text { From December to } \\
\text { May }\end{array}$ & yellow & Crops \\
\hline cotton & $\begin{array}{l}\text { From April to } \\
\text { September }\end{array}$ & white & Crops \\
\hline
\end{tabular}

\section{The design of art farmland to rural landscape planning}

Art concept of farmland is from the aesthetic point of view, based on the agricultural production and the leisure entertainment.This design applied in the rural landscape planning can widen the 
development road of agricultural production. At the same time,the different art farmlands label different village.It is important for the rural planning and development.

Ornamental

We'd better watch the art farmland from a distance.Entering the field, we can watch the process of farming production and different stages of the crop growth, blossom, fruiting landscape, also can be in the flower river scenic landscape to watch waterscape and aquaculture. We can achieve the artistic effect in different seasons and the crops seasonal changes of landscape is the best landscape.

\section{Participation}

Art farmland not only can be watched,but also can be participated in. The visitor will be allowed to sketch,take a picture and experience farming activities. This activity is interesting and we can publicize the project through it.

The originality of farmland landscape

Farmland is not only the base of agricultural production, but also is a special landscape to attract tourists.Japan had launched the "one village,one landscape" policy.

\section{Conclusion}

The planning and design of the West Valley Ecological town which located in Zhongshan Community, Shui kou Town, Qiong lai City is totally according to the principles of holistic that without destroying the original customs, habits and topography. Therefore, it both heritage the local customs and promote the farming culture.The "Mondrian's lattice" labels this town.The design of art farmland not only adds more artistic effect to Xihe valley town but also attracts a lot of tourists.In the end,this design lay a foundation for the development of tourism industry in the future of the project area。

\section{Acknowledgements}

This study is financially supported by the National Non-profit Research Foundation for Meteoro logy (GYHY201506016), Open Research Fund Program of the Meteorological Center for Huaihe w atershed (HRM200905).

\section{References}

[1]Songyang Liu,Yuankai Hou,Yan Xiang.Landscape Features and Design Research of art farmland[J].Northern Horticulture.2009,(10):234-238.

[2]Guibo Liu, Zongli Yang,.Ecological Function Research of Diversity Farmland Landscape[J].Eco-Agriculture research. 1994, 4(2): 49-56.

[3]Yuanliang Dong, Junshan Ma, Chengcheng Pan.Application of Open - air Museum Concept Landscape Projects:A Study Case of Rural Case Landscape Design at Jubao Bay in Jiaxing,Zhejiang[J].Journal of Chinese Urban Forestry.2013,11(1):38-41.

[4]Min Zhang.The unity of productive and aesthetic of the agricultural landscape[J].Hunan Social Sciences.2004,(3):10-12. 